\title{
PENGARUH OTONOMI DAERAH DAN MANAJEMEN BERBASIS SEKOLAH TERHADAP PENINGKATAN MUTU PENDIDIKAN MENENGAH ATAS DI KAB. TANGERANG
}

\section{THE IMPACT OF REGIONAL AUTONOMY AND SCHOOL BASED MANAGEMENT ON QUALITY IMPROVEMENT OF SECONDARY HIGH EDUCATION IN TANGERANG DISTRICT}

\author{
Deden Saeful Ridhwan dan Leni Nurmiyanti \\ Sekolah Tinggi Ilmu Tarbiyah (STIT) Islamic Village Tangerang. \\ Email: dedensaeful_ridhwan@yahoo.com \\ Email: leni_nurmiyanti@yahoo.co.id
}

Naskah diterima 15Oktober 2016, direvisi 10 November 2016, disetujui 15 November 2016

\begin{abstract}
Abstrak
The School Based Management Program (MBS) can assist in supporting the quality improvement of education in each region, so each region can empower participation and role of community in managing education. In order to find out significance of the impact of Regional Autonomy (OTDA) and MBS on Quality Improvement of Secondary High Education, then a research is made in Pangedagan SubDistrict. Methods used in the research are survey and quantitative method namely a method describing and analyzing a certain phenomenon or object researched and observed with correct interpretation. The use of this method is aimed to problem solving. Data collection technique uses questionnaire and literature research. Based on the performed research, the Impact of Regional Autonomy on Educational Quality Improvement is 0.582. The Impact of MBS on Educational Quality Improvement is 0.647 and the Impact of Regional Autonomy and MBS on Educational Quality Improvement is 0.706 .
\end{abstract}

Keywords: Regional Autonomy, School Based Management, Educational Quality
Abstrak

Program Manajemen Berbasis Sekolah (MBS) dapat membantu dalam mendukung peningkatan mutu pendidikan ditiap daerah, sehingga masing-masing daerah dapat memberdayakan partisipasi serta peran masyarakat dalam mengelola pendidikan. Dalam rangka mengetahui sejauh mana pengaruh Otonomi Daerah dan MBS terhadap Peningkatan Mutu Pendidikan Menengah Atas maka di lakukan penelitian di wilayah Kecamatan Pagedangan. Metode yang digunakan dalam penelitian ini adalah metode survey dan metode kuantitatif yaitu suatu metode yang didalamnya mendeskripsikan dan menganalisa suatu fenomena atau objek tertentu yang diteliti dan diamati dengan interpretasi yang tepat. Penggunaan metode ini tertuju pada pemecahan masalah. Teknik pengumpulan data menggunakan angket dan penelitian kepustakaan. Berdasarkan hasil penelitian yang telah dilakukan, maka diperoleh hasil Pengaruh Otonomi Daerah terhadap Peniningkatan Mutu Pendidikan adalah 0,582. Pengaruh MBS terhadap Peningkatan Mutu Pendidikan adalah 0.647 dan Pengaruh Otonomi Daerah dan MBS terhadap Peningkatan Mutu Pendidikan adalah 0,706.

Kata Kuncit: Otonomi Daerah, Manajemen Berbasis Sekolah, Mutu Pendidikan 


\section{PENDAHULUAN}

Otonomi pendidikan diharapkan dapat meningkatkan mutu pendidikan, Sekolah dapat mengelola manajemen pendidikan secara independen sesuai dengan kebutuhan dan ciri kekhasan daerah masing-masing, sehingga mutu pendidikan dapat diterima oleh masyarakat dan daerah tersebut. Otonomi pendidikan juga menghadirkan Manajemen Berbasis Sekolah (MBS) yang mampu meningkatkan mutu sesuai dengan keadaan dan kondisi masing-masing daerah. Karena dengan MBS sekolah dapat memberdayakan partisipasi serta peran masyarakat dalam mengelola pendidikan meliputi jenis pendidikan dan kurikulum program pendidikan.

Berbagai permasalahan yang terjadi di dunia pendidikan Indonesia tidak bisa dilepaskan dari ketidaksiapan para pelaksana pendidikan seperti dalam permasalahan pemerataan pendidikan, mutu pendidikan, efisiensi pendidikan dan relevansi pendidikan dalam peningkatan mutu pendidikan. Atas dasar hal tersebut di atas maka penulis tertarik untuk meneliti "Pengaruh Otonomi Daerah dan Manajemen Berbasis Sekolah Terhadap Peningkatan Mutu Pendidikan Menengah Atas".

Penelitian ini dapat dirumuskan sebagai berikut: (1). Apakah Otonomi Daerah berpengaruh terhadap Peningkatkan Mutu Pendidikan Menengah Atas di Wilayah Kecamatan Pagedangan ? (2). Apakah Manajemen Berbasis Sekolah berpengaruh terhadap Peningkatkan Mutu Pendidikan Menengah Atas di Wilayah Kecamatan Pagedangan ? (3). Apakah Otonomi Daerah dan Manajemen Berbasis Sekolah berpengaruh terhadap Peningkatkan Mutu
Pendidikan Menengah Atas di Wilayah Kecamatan Pagedangan ?. Tujuan dari studi ini adalah untuk membuktikan seberapa besar pengaruh Otonomi Daerah dan Manajemen Berbasis Sekolah Terhadap Peningkatkan Mutu Pendidikan Menengah Atas di Wilayah Kecamatan Pagedangan.

\section{Kajian Literatur}

\section{Otonomi Daerah}

Secara etimologi, kata otonomi berasal dari bahasa latin "autos" yang berarti sendiri dan "nomos" yang berarti aturan. ${ }^{1}$ Maka otonomi dapat berarti "peraturan sendiri" atau mempunyai hak/ kekuasaan/ kewenangan untuk membuat peraturan sendiri, arti tersebut dikembangkan menjadi "pemerintah sendiri". ${ }^{2}$ Dengan adanya otonomi daerah diharapkan pemerintah daerah dapat mengembangkan dan meningkatkan serta mendukung perkembangan potensi daerahnya masingmasing yang meliputi seluruh bidang pemerintahan kecuali politik luar negeri, hankam, peradilan, moneter dan fiskal, agama, serta 'kewenangan bidang lain' dalam wujud otonomi luas, nyata dan bertanggung jawab. Otonomi daerah yang tertuang dalam peraturan perundang-undangan, secara subtansial menunjukan bahwa kabupaten dan kota memegang peranan penting dalam kewenangan dan pembiayaan. Demikian halnya dengan pengembangan pendidikan, sangat bergantung atas

${ }^{1}$ Untuk lebih jelasnya pembahasan tentang ini, lihat, A. Ubaedillah, 2014. Pendidikan Kewarganegaraan (civic Education). Jakarta: Kencana, h. 176.

${ }^{2}$ Umaedi. 2004. Manajemen Mutu Berbasis Sekolah/ Madrasah. Jakarta: Pusat Kajian Manajemen Mutu Pendidikan, h. 19. 
kebijakan pemerintah daerah sebagai bagian dari kewenangan yang dilimpahkan melalui otonomi pengelolaan pendidikan yang diharapkan mampu untuk memenuhi kebutuhan masyarakat secara lebih cepat, tepat, efisien dan efektif.

\section{Otonomi Pendidikan}

Otonomi pendidikan merupakan hasil dari adannya otonomi daerah yang terjadi padasaatreformasidiInodnesia.Berdasarkan Undang-undang No. 20 Tahun 2003 tentang Sistem Pendidikan Nasional yang mengatur dan memberikan otoritas penuh kepada tiap sekolah untuk melakukan otonomi sekolah. Dalam pasal 51 ayat 1 yang berbunyi "Pengelolaan satuan pendidikan anak usia dini, pendidikan dasar, dan pendidikan menengah dilaksanakan berdasarkan standar pelayanan minimal dengan prinsip manajemen berbasis sekolah" dan pasal 52 "Pengelolaan satuan pendidikan tinggi dilaksanakan berdasarkan prinsip otonomi, akuntabilitas, jaminan mutu, dan evaluasi yang transparan". ${ }^{3}$ Otonomi pendidikan pada dasarnya dapat dipahami sebagai pemberian sebagian kewenangan, hak dan kebijakan pada sekolah untuk dapat meningkatkan mutu pendidikan sesuai dengan ciri dan kekhasaan dari daerah yang berada di wilayah masing-masing. ${ }^{4}$ Dalam otonomi pendidikan kewenangan penyelenggaran pendidikan berada dalam tanggung jawab pemerintah kota/kabupaten.

${ }^{3}$ Lihat UUSPN Tentang Sistem Pendidikan Nasional Nomor 20 Tahun 2013

${ }^{4}$ Adiwikarta Sudardja. 1988. Sosiologi Pendidikan: Isyu dan Hipotesis tentang Hubungan Pendidikan dengan Masyarakat. Jakarta: Ditjen Dikti Depdikbud, h. 110.

\section{Konsep Manajemen Berbasis Sekolah}

Konsep manajemen berbasis sekolah merupakan salah satu upaya dalam rangka menciptakan keunggulan masyarakat serta bangsa dalam menguasai ilmu dan teknologi, diharapkan dengan hal tersebut di atas dapat menjadi landasan pengembangan pendidikan yang berkualitas dan berkelanjutan, baik secara mikro, meso, maupun makro. ${ }^{5}$

Tujuan utama MBS adalah meningkatkan efisiensi, mutu dan pemerataan pendidikan. Peningkatan efisiensi diperoleh melalui keleluasaan mengelola sumber daya yang ada, partisipasi masyarakat, ${ }^{6}$ dan penyederhanaan birokrasi. Peningkatan mutu diperoleh melalui partisipasi orang tua, kelenturan pengelolaan sekolah, peningkatan profesionalisme guru, adanya apresiasi dan hukuman adalah sebagai elemen kontrol, serta hal lain yang dapat menumbuh kembangkan suasana yang kondusif. Implementasi manajemen berbasis sekolah menuntut dukungan tenaga kerja yang terampil dan berkualitas agar dapat membangkitkan motivasi kerja yang lebih produktif dan mengefisiensikan sistem serta memberdayakan otoritas daerah setempat untuk menghilangkan birokrasi yang tumpang tindih.

${ }^{5}$ Rodney T. Ogawa \& Paula A. White, dalam Susan Albers Mohman. 1994. School Based Management, Organizing for High Performance. San Francisco: JosseyBass Publisher, h. 53-54.

6 Abuddin Nata. 2001. Pendidikan Berbasis Masyarakat dalam Perspektif Islam. Jakarta: Jauhar Jurnal Pemikiran Islam Kontekstual, Volume 2. Nomor 2. h. 189. 


\section{Strategi Peningakatan Mutu}

Strategi perbaikan mutu ${ }^{7}$ yang berkelanjutan dapat dirumuskan kedalam dua strategi: (a). Analisis kesenjangan mutu pendidikan. (b). Pemenuhan standar acuan mutu oleh satuan pendidikan, dengan pemenuhan standar acuan mutu berupa pencapaian SMP dan SNP merupakan bagian dari upaya peningkatan mutu pendidikan. Tahapan kegiatan satuan pendidikan pemenuhan pada satuan pendidikan adalah sebagai berikut: Pertama, Pengumpulan data satuan pendidikan melakukan sosialisasi cara pengisian alat evaluasi diri satuan oleh pengawas dan kepala sekolah kepada sivitas satuan pendidikan, melakukan pengisian EDS dengan standar acuan SMP atau SNP. Kedua, Analisis data, mengecek kebenaran data tersebut dilengkapi dengan buktibukti yang faktual, mengolah sesuai dengan indikator dan kategori yang terdapat pada EDS, sehingga diperoleh hasil analisa yang lebih baik dalam mengembangkan mutu satuan pendidikan. ${ }^{8}$

Ketiga, Pelaporan, dengan mengidentifikasi pelaporan agar dapat disusun dan menghasilkan laporan yang sesuai dengan fakta di lapangan. Keempat. Rekomendasi, yakni mendiskusikan hasil analisis dan pelaporan untuk menentukan rekomendasi apa yang dapat diajukan untuk meningkatkan mutu pendidikan, menganalisistemuan-temuanyangdiperoleh pada analisis data sehingga rekomendasi yang diajukan sesuai dengan hasil evaluasi. Kelima, Dimensi-dimensi perbaikan mutu

${ }^{7}$ Marus Suti. 2011. Strategi Peningkatan Mutu di Era Otonomi Pendidikan. Jurnal MEDTEK, Volume 3. Nomor 2. h. 2.

${ }^{8}$ Bonsting, J.J. 2001. Quality of School . California : Corwin Press, h. 14 pendidikan. Seperti: regulasi, implementasi dan pengendalian (identifikasi kelemahankelemahan). Keenam, Supervisi sebagai strategi perbaikan mutu. Dilakukan oleh pemerintah pusat, provinsi, kabupaten/ kota, dan penyelenggara satuan pendidikan. Sementara masyarakat melakukan pengawasan terhadap satuan/program pendidikan.

\section{Kerangka Teori}

Otonomi Daerah yang menghadirkan Otonomi Pendidikan yang dapat dimaknai secara sederhana, dimana sebagian dari perlimpahan kewenangan dan tugas pemerintah pusat dilaksanakan ditingkat lokal atau daerah. Kewenangan serta tanggung jawab Otonomi Pendidikan pada Otonomi Daerah diserahkan pada pemerintah kota/kabupaten, dengan harapan kemampuan masing-masing daerah otonom sangat menentukan prinsip penerapan Otonomi Pendidikan agar sekolah dapat meningkatkan mutu pendidikannya. ${ }^{9}$

Kewenangan yang bertumpu pada sekolah yang merupakan inti dari MBS dipandang mampu memberikan kontribusi yang positif dalam peningkatan mutu pendidikan. ${ }^{10}$ Hadirnya MBS di Indonesia dikarenakan beberapa faktor diantaranya: letak geografis yang sangat luas, Aneka ragam golongan dan lingkungan sosial, budaya, agama, ras dan etnik serta bahasa.

${ }^{9}$ Fasli Jalal dan Dedi Supriadi, 2001, Reformasi Pendidikan dalam Konteks Otonomi Daerah. Jakarta, Adicipta Karya Nusa, h. 155. Lihat juga Umul Hidayati, 2007, Permasalahan Madrasah Era Otonomi Daerah . Jakarta: Jurnal Edukasi, Volume 5. Nomor 1. h. 118.

10 Umaedi, 2004, Manajemen Mutu Berbasis Sekolah/Madrasah. Jakarta: Pusat Kajian Manajemen Mutu Pendidikan, h. 326. 
Besarnya jumlah dan banyaknya jenis populasi pendidikan yang tumbuh sesuai dengan perkembangan ekonomi, iptek, perdagangan dan sosial budaya, Perluasan lingkungan dan gaya hidup di suatu daerah, perkembangan sosial politik, ekonomi, budaya yang cepat serta dinamis.

\section{Hipotesis}

Berdasarkan rumusan masalah di atas maka hipotesis penelitian ini sebagai berikut: (1). Di Duga Otonomi Daerah berpengaruh terhadap Peningkatan Mutu Pendidikan Menengah Atas di Wilayah Kecamatan Pagedangan. (2). Di Duga Manajemen Berbasis Sekolah berpengaruh terhadapPeningkatan Mutu Pendidikan Menengah Atas di Wilayah Kecamatan Pagedangan. (3). Di Duga Otonomi Daerah dan Manajemen Berbasis Sekolah secara bersama-sama berpengaruh terhadap Peningkatan Mutu Pendidikan Menengah Atas di Wilayah Kecamatan Pagedangan.

\section{METODOLOGI PENELITIAN}

Penelitian ini menggunakan desain survey yaitu teknik pengumpulan dan analisis data berupa opini dari variabelvariabel yang diteliti melalui penyebaran kuesioner. Kuesioner yang disebarkan pada responden yang bersifat tertutup. Skala Likert digunakan untuk mengukur sikap, pendapat, dan persepsi seseorang atau sekelompok orang tentang fenomena sosial. Skala likert mempunyai gradasi dari sangat positif sampai sangat negatif. Maka dengan demikian penulis bermaksud akan menyusun dan menganalisa serta mendeskripsikan secara rasional, empiris, sistematis mengenai segala gejala-gejala yang akan diteliti dengan metode ilmiah dalam memecahkan variabel-variabel Otonomi Daerah dan Manajemen Berbasis Sekolah terhadap Peningkatan Mutu Pendidikan Menengah Atas pada SMA/ sederajat di Wilayah Kecamatan Pagedangan.

Penelitian ini menggunakan metode kuantitatif dan instrumen yang akan digunakan adalah kuesioner, hasil pengukuran variabel-variabel yang dioperasionalkan dengan menggunakan instrumen dengan tujuan untuk mengetahui pengaruh dari tiap-tiap varibel yang telah ada. Dalam penelitian ini akan mengunakan jawaban-jawaban yang akan diberikan oleh responden lalu dianalisis sesuai dengan kondisi serta kenyataan yang ada sehingga dapat menghasilkan data-data valid, reliabel serta obyektif. Penelitian ini mengunakan tiga variabel, dimana dua variabel terikat dan satu variabel bebas dan dikelompokkan dalam simbol :

$$
\begin{gathered}
\text { Gambar } 1 \\
\text { Desain Penelitian }
\end{gathered}
$$

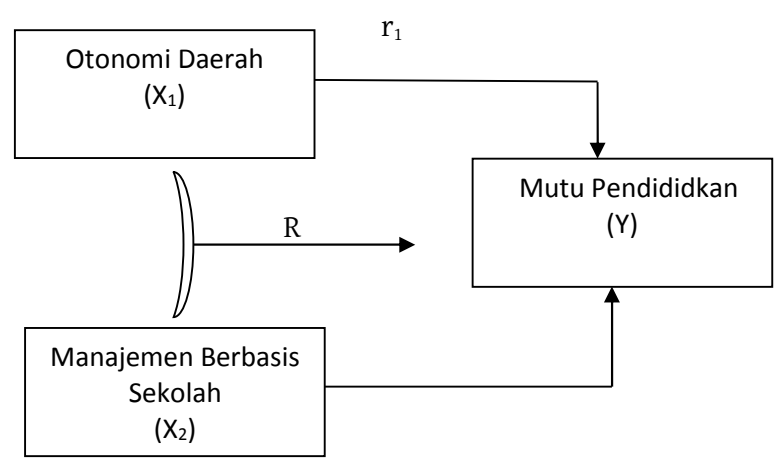

Keterangan : $\mathrm{X}_{1}=$ Variabel Bebas $1, \mathrm{X}_{2}$ = Variabel Bebas 2, $Y=$ Variabel Terikat, $r_{1}=$ Hubungan $X_{1}$ dengan $Y, r_{2}=$ Hubungan $X_{2}$ dengan $Y$, dan $R=$ Hubungan antara $X_{1}$ dan $X_{2}$ terhadap $Y$. 
Populasi yang akan dijadikan kajian penelitian ini adalah guru Sekolah Menengah Atas di wilayah Kecamatan Pagedangan meliputi :

Tabel 1

Jumlah Populasi

\begin{tabular}{|c|l|c|c|c|c|}
\hline \multirow{2}{*}{ No } & \multirow{2}{*}{ Nama Sekolah } & \multicolumn{3}{|c|}{ Pendidikan Terakhir } & \multirow{2}{*}{ Total } \\
\cline { 3 - 5 } & & SMA & S1 & S2 & \\
\hline 1 & SMA 22 & 0 & 36 & 2 & 38 \\
\hline 2 & SMK6 & 2 & 31 & 1 & 34 \\
\hline 3 & SMA Imtek & 2 & 13 & 1 & 16 \\
\hline 4 & MA Nurul Falah & 2 & 12 & 2 & 16 \\
\hline \multicolumn{2}{|c|}{ Jumlah } & $\mathbf{6}$ & $\mathbf{9 2}$ & $\mathbf{6}$ & $\mathbf{1 0 4}$ \\
\hline
\end{tabular}

Pengambilan sampel dilakukan dengan menggunakan teknik acak sederhana (simple random sampling) dimana setiap anggota populasi mempunyai peluang yang sama untuk diambil menjadi anggota sampel. Untuk menentukan sampel yang akan digunakan dalam penelitian ini adalah rumus Slovin.

Jumlah responden yang akan diteliti sebanyak 51 Responden dan jumlah reponden tiap sekolah sebanyak :

Tabel 2

Jumlah Sampel

\begin{tabular}{|l|l|c|c|c|c|}
\hline \multirow{2}{*}{ No } & \multirow{2}{*}{ Nama Sekolah } & \multicolumn{3}{|c|}{ Pendidikan Terakhir } & \multirow{2}{*}{ Total } \\
\cline { 3 - 5 } & & SMA & S1 & S2 & \\
\hline 1 & SMA 22 & 0 & 16 & 2 & 18 \\
\hline 2 & SMK6 & 2 & 14 & 1 & 17 \\
\hline 3 & SMA Imtek & 2 & 5 & 1 & 8 \\
\hline 4 & MA Nurul Falah & 2 & 4 & 2 & 8 \\
\hline \multicolumn{2}{|l|}{ Jumlah } & 6 & 39 & 6 & 51 \\
\hline
\end{tabular}

Teknik Pengumpulan Data dilakukan melalui: Pertama, Penelitian kepustakaan (Library Research), yaitu dengan cara membaca dari buku-buku dan sumbersumber kepustakaan lainnya yang selanjutnya di analisa. Kedua, Kuesioner. Dilakukan dengan cara memberi seperangkat pertanyaan yang menggunakan Skala Likert dengan gradasi jawaban dari Sangat Setuju (SS) Sampai Sangat Tidak Setuju (STS).

Teknik analisis data menggunakan metode statistikdengan menggunakan Program SPSS for Windows Versi 17. Dalam mengukur tingkat kepercayaan terhadap suatu penelitian, maka diperlukanlah uji validitas instrument dan reliabilitas instrument, ${ }^{11}$ yaitu :

Pertama Uji Normalitas, yaitu digunakan untuk menguji data-data yang akan diteliti apakah data tersebut berdistribusi normal atau tidak. Untuk menguji normalitas data digunakan cara uji Chi Kuadrat dengan rumus sebagai berikut:

$$
x^{2}=\sum_{\mathrm{l}=1}^{\mathrm{k}} \frac{\left(f_{0}-f_{e}\right)^{2}}{f^{n}}
$$

Keterangan :

$x^{2}=$ Nilai Chi-Square yang dicari

$f_{0}=$ Frekuensi hasil pengamatan

$f_{e}=$ Frekuensi yang diharapkan

Selanjutnya membandingkan $\mathrm{X}^{2}$ hitung dengan $\mathrm{x}^{2}$ tabel dengan taraf kesalahan 0,05 $\mathrm{jika}^{\mathrm{X}^{2} \text { hitung }} \geq^{\mathrm{X}^{2} \text { tabel }}$ maka berdistribusi normal.

Kedua Uji Validitas Kuesioner, dalam menguji keabsahan dan kevalidan alat ukur atau intrument penelitian, terlebih dahulu dicari nilai korelasi dengan mengunakan rumus koefisien korelasi Product Moment Pearson :

${ }^{11}$ Sugiyono. 2008. Metode Penelitian Kuantitatif Kualitatif Dan R \&D. Bandung: Alfabeta, h. 243 


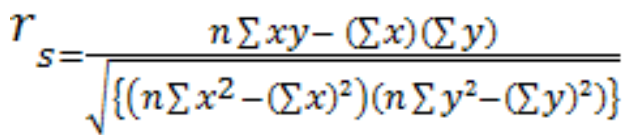

Keterangan :

$r_{s}=$ Koefisien korelasi interval

$\mathrm{x}=$ Jumlah skor tiap item

y = Jumlah skor total seluruh item

$\mathrm{n}$ = Jumlah responden

Koesioner dinyatakan valid adalah $\mathrm{r}=$ 0.30 jika korelasi antar butir dengan skor total kurang dari 0.30 maka butir dalam intrument tersebut dinyatakan tidak valid.

Ketiga Uji Reliabilitas, Hasil uji reliabilitas diasumsikansebagai parameter yang menyatakan kehandalan alat intrument. Pengujian reliabilitas dapat digunakan dengan menggunakan metode Alpha Crombach :

$$
r_{l l}=\frac{\left(\frac{k}{k-l}\right)}{l-\left(\frac{\sum \sigma b^{2}}{\sigma_{t^{2}}}\right)}
$$

Keterangan :

$r_{l l}=$ Reliabilitas Intrument

$k$ = Banyaknya soal

$\sigma_{b}=$ Jumlah varians butir

$\sigma_{t}=$ Jumlah varians total

Setelah penghitungan Alpha Crombach selanjutnya diuji signifikansinya dengan kriteria penghitungan: koefisien reliabilitas dianggap signifikan jika nilai $r$ hasil perhitungan $\geq 0.70$. Setelah data terkumpul maka selanjutnya data tersebut dianalisa dengan menggunakan analisa deskriftif. Analisa deskriftif kuantitatif adalah Pengukuran dan interprestasi dari data- data yang dihasilkan dalam penelitian yang berwujud angka-angka dan analisa deskriftif yaitu hasil kesimpulan dari datadata penelitian yang dinyatakan kedalam kalimat.

Keempat Uji Koefisien Korelasi, dalam penelitian ini penulis menggunakan jenis hipotesa asosiatif, data yang dikorelasikan berbentuk interval dari sumberdata yang sama. Teknik pengujian yang akan digunakan adalah korelasi Pearson Product Moment (r). Uji korelasi koefisien digunakan untuk mengetahui derajat pengaruh variabel terikat terhadap variabel bebas dan variabel bebas terhadap variabel bebas yang lainya. Secara umum rumusan korelasi product moment dapat dinyatakan dengan :

$$
\begin{aligned}
\mathrm{r}_{\mathrm{xy}} & =\frac{\Sigma x y}{\sqrt{\left(\Sigma x^{2}\right)\left(\Sigma y^{2}\right)}} \\
\mathrm{r}_{\mathrm{xy}} & =\mathrm{n} \Sigma \mathrm{x}_{\mathrm{i}} \mathrm{y}_{\mathrm{i}}-\left(\Sigma \mathrm{x}_{\mathrm{i}}\right)\left(\Sigma \mathrm{y}_{\mathrm{i}}\right)
\end{aligned}
$$

$$
\sqrt{\left\{n \sum x_{i^{2}}-\left(\sum x_{i}\right)^{2}\right\}}\left\{n \sum y_{i^{2}}-\left(\sum y_{i}\right)^{2}\right\}
$$

Keterangan :

$$
\begin{aligned}
\mathrm{r}_{\mathrm{xy}} & \quad=\text { Koefisien korelasi } \\
\mathrm{n}= & \text { Jumlah responden } \\
\mathrm{x}_{\mathrm{i}}= & \text { Variabel bebas ke-i } \\
\mathrm{y}_{\mathrm{i}}= & \text { Variabel terikat ke-i } \\
\Sigma \mathrm{x}_{1}^{2}= & \text { Kuadrat jumlah skor variabel } \\
& \text { bebas ke }-1 \\
\Sigma \mathrm{x}_{2}^{2}= & \text { Kuadrat jumlah skor variabel } \\
& \text { bebas ke- } 2 \\
\Sigma \mathrm{y}^{2}= & \text { Kuadrat jumlah skor variabel } \\
& \text { terikat (y) }
\end{aligned}
$$

Sedangkan untuk mengetahui derajat signifikansi hubungan antara variabel yang satu dengan variabel yang lainnya, 
perlu dilakukan uji signifikansi dengan menggunakan rumus t sebagai berikut:

$$
t_{\text {hitung }}=r \sqrt{n-2}
$$

Selanjutnya harga $\mathbf{t}$ hitung tersebut dibandingan dengan $\mathbf{t}$ tabel dengan ketentuan sebagai berikut :

- Jika t hitung > t tabel

Ho ditolak Ha diterima

(terdapat hubungan yang signifikan)

- Jika t hitung < t tabel

Ho diterima Ha ditolak

(tidak ada hubungan yang signifikan)

Uji signifikansi korelasi product moment secara praktis, yang tidak perlu dihitung namun langsung dihubungkan dengan tabel $\mathrm{r}$ product moment. Dengan ketentuan nilai $r$ pada tingkat kesalahan 5\% adalah bila $r$ hitung lebih kecil dari tabel maka Ho diterima dan Ha ditolak, namun sebaliknya bila $r$ hitung lebih besar dari $r$ tabel $\left(r_{h}>r_{t}\right)$ maka Ha diterima, setelah mendapatkan hasilnya kemudian di analisa korelasi dengan menghitung koefisien determinasi dengan cara mengkuadratkan koefisien $r$ hitung yang ditemukan. Untuk mengetahui apakah terdapat hubungan antara variabel tersebut dapat digunakan pedoman sebagai berikut:

Tabel. 3

Koefisien Korelasi

\begin{tabular}{|c|c|}
\hline Interval Koefisien & Tingkat Hubungan \\
\hline $0,00-0,199$ & Sangat rendah \\
$0,20-0,399$ & Rendah \\
$0,40-0,599$ & Sedang \\
$0,60-0,799$ & Kuat \\
$0,80-1,000$ & Sangat Kuat \\
\hline
\end{tabular}

Kelima Korelasi Berganda, analisis koefisien korelasi berganda digunakan untuk menilai tingkat keeratan hubungan antara $\mathrm{Y}$ dengan $\mathrm{X}_{1}$ dan $\mathrm{X}_{2}$. Secara bersamasama. Tinggi rendahnya tingkat hubungan antara varibel dapat dilihat dari besar atau kecilnya koefisien nilai korelasi (R) dengan menggunakan rumus :

$R$

$y x_{1} x_{2}=\frac{\sqrt{r^{2 y x 1}-r^{2 y x 2}-2 r y x 1 . r y x 2 . r x 1 x 2}}{1-r^{2 y x 1 \times 2}}$

Keenam Uji Regresi Linear, Uji regresi linear ini terdapat dua alat analisis, yang pertama, Regresi linear sederhana adalah alat analisis yang digunakan untuk memprediksi variabel terkait dengan melihat sifat hubungan dan besar atau kecilnya pengaruh antara $\mathrm{Y}$ dengan $\mathrm{X}_{1}$ dan $X_{2}$. Adapun alat analisis regresi linear sederhana yang digunakan adalah sebagai berikut $^{12}$ :

$$
\hat{\mathrm{Y}}=a+b X
$$

Keterangan :

$\hat{Y}=$ Prediksi variabel $Y$

$\mathrm{a}=$ Konstanta

$\mathrm{b}=$ Koefisien regresi

$\mathrm{X}$ = Subjek variabel bebas

Kedua Regresi linier berganda adalah alat analisis yang digunakan untuk memprediksi variabel terkait dengan melihat sifat hubungan serta besar atau kecilnya pengaruh antara $Y$ dengan variabel $\mathrm{X}_{1}$ dan $\mathrm{X}_{2}$. Sifat hubungan dan besar atau kecilnya pengaruh antara variabel yang

${ }^{12}$ Sugiyono, 2008, Metode Penelitian Kuantitatif Kualitatif Dan R \&D. Bandung: Alfabeta, h. 218 
diteliti dapat dilihat dari tanda $(+/-) .{ }^{13}$ rumus regresi liner berganda :

$$
\begin{aligned}
& \hat{Y}=a+b_{1} X_{1}+b_{2} X_{2} \\
& \text { Keterangan : } \\
& \hat{Y}=\text { Prediksi variabel } Y \\
& a=\text { Konstanta } \\
& b_{1}=\text { Koefisien regresi variabel } X_{1} \\
& b_{2}=\text { Koefisien regresi variabel } X_{2} \\
& X_{1}=\text { Variabel } X_{1} \\
& X_{2}=\text { Variabel } X_{2}
\end{aligned}
$$

Untuk menguji signifikansi korelasi berganda menggunakan formula $\mathrm{F}-\mathrm{h}$ atau Uji F dengan rumus sebagai berikut:

$$
\mathrm{F}_{\mathrm{h}}=\frac{R^{2} / K}{\left(1-R^{2}\right) /(n-K-1)}
$$

Keterangan :

$\mathrm{F}_{\mathrm{h}}=\mathrm{Uji}_{\text {hitung }}$

$\mathrm{R}=$ Koefisien korelasi ganda

$\mathrm{K}=$ Jumlah variabel terikat

$\mathrm{n}$ = Jumlah anggota sampel

Kriteria pengujian hipotesis sebagai berikut :

- Jika nilai $\mathrm{F}_{\text {tes }}<$ nilai $\mathrm{F}_{\text {tabel }}$ maka $\mathrm{H}_{\mathrm{a}}$ ditolak $\mathrm{H}_{\mathrm{o}}$ diterima

- Jika nilai $\mathrm{F}_{\text {tes }}>$ nilai $\mathrm{F}_{\text {tabel }}$ maka $\mathrm{H}_{\mathrm{a}}$ ditolak $\mathrm{H}_{\mathrm{o}}$ diterima

Tempat penelitian dilakukan pada SMA/ Sederajat di wilayah Kecamatan Pagedangan. Dengan mengambil empat sekolah dianggap repersentatif yang ada diwilayah Kec

13 Sugiyono, 2008, Metode Penelitian Kuantitatif Kualitatif Dan R \&D. Bandung: Alfabeta,h. 224.
Pagedangan. Empat sekolah tersebut adalah: 1). SMA $22 \mathrm{Kab}$.Tangerang, terletak di kecamatan Pagedangan dan menjadi satusatunya SMA Negri di Pagedangan. 2). SMK $6 \mathrm{Kab}$. Tangerang, terletak di kecamatan Pagedangan dan menjadi satu-satunya SMK Negri di Pagedangan. 3). SMA Imtek, terletak di kecamatan Pagedangan dan menjadi perwakilan SMA Swasta yang akan di teliti. 4). MA Nurul Falah, Madrasah Aliyah Swasta yang terdapat di Kecamatan Pagedangan yang mewakili Madrasah Aliyah. Yang terdiri dari dua sekolah negeri dan dua sekolah swasta, pertimbangan memilih lokasi tersebut diatas berdasarkan kelayakan objek yang memungkinkan mendapat informasi dalam menunjang tercapainya tujuan penelitian serta adanya variasi dari SMA/Sederajat yang ada di wilayah Kec Pagedangan.

\section{HASIL DAN PEMBAHASAN}

\section{Deskripsi Data}

Data yang dihasilkan dalam penelitian ini akan di deskripsikan berdasarkan skor terendah dan skor tertinggi sehingga akan terlihat rentang datanya, rata-rata, standar deviasi, modus, median, varian dan distribusi frekuensi yang disertai dengan histogram. Data-data yang dihasilkan dalam penelitian ini dihitung dengan menggunakan Program SPSS for Windows Versi 17.

\section{Deskripsi Data Otonomi Daerah $\left(\mathbf{X}_{1}\right)$}

Hasil penelitian atas pengaruh Otonomi Daerah terhadap Peningkatan Mutu Pendidikan Menengah Atas yang telah peneliti lakukan di Kecamatan Pagedangan Kabupaten Tangerang adalah sebagai berikut: 
Tabel. 4

Hasil Persepsi Responden Otonomi Daerah

\begin{tabular}{|c|c|c|c|c|c|c|c|c|c|c|c|c|}
\hline \multirow{2}{*}{$\begin{array}{c}\text { No.Item } \\
\text { Pertanyaan }\end{array}$} & \multicolumn{2}{|c|}{ STS } & \multicolumn{2}{|c|}{ TS } & \multicolumn{2}{|c|}{$\mathrm{RR}$} & \multicolumn{2}{|c|}{$\mathrm{s}$} & \multicolumn{2}{|c|}{ SS } & \multicolumn{2}{|c|}{ Skor Total } \\
\hline & $\mathrm{F}$ & $\%$ & $\mathrm{~F}$ & $\%$ & $\mathrm{~F}$ & $\%$ & $\mathrm{~F}$ & $\%$ & $\mathrm{~F}$ & $\%$ & $\mathrm{~F}$ & $\%$ \\
\hline 1 & 0 & 0 & 7 & 14 & 12 & 23 & 25 & 49 & 7 & 14 & 51 & 100 \\
\hline 2 & 0 & 0 & 0 & 0 & 6 & 11 & 38 & 75 & 7 & 14 & 51 & 100 \\
\hline 3 & 0 & 0 & 0 & 0 & 11 & 21 & 32 & 63 & 8 & 16 & 51 & 100 \\
\hline 4 & 0 & 0 & 13 & 26 & 14 & 27 & 21 & 41 & 3 & 6 & 51 & 100 \\
\hline 5 & 0 & 0 & 19 & 37 & 10 & 20 & 19 & 37 & 3 & 6 & 51 & 100 \\
\hline 6 & 1 & 2 & 1 & 2 & 3 & 6 & 35 & 69 & 11 & 21 & 51 & 100 \\
\hline 7 & 0 & 0 & 1 & 2 & 4 & 8 & 33 & 65 & 13 & 25 & 51 & 100 \\
\hline 8 & 2 & 4 & 12 & 24 & 13 & 25 & 19 & 37 & 5 & 10 & 51 & 100 \\
\hline 9 & 1 & 2 & 9 & 18 & 11 & 21 & 26 & 51 & 4 & 8 & 51 & 100 \\
\hline 10 & 1 & 2 & 6 & 12 & 14 & 27 & 27 & 53 & 3 & 6 & 51 & 100 \\
\hline 11 & 1 & 2 & 10 & 20 & 15 & 29 & 23 & 45 & 2 & 4 & 51 & 100 \\
\hline 12 & 1 & 2 & 3 & 6 & 3 & 6 & 30 & 59 & 14 & 27 & 51 & 100 \\
\hline 13 & 0 & 0 & 3 & 6 & 12 & 24 & 22 & 43 & 14 & 27 & 51 & 100 \\
\hline 14 & 1 & 2 & 19 & 37 & 20 & 39 & 9 & 18 & 2 & 4 & 51 & 100 \\
\hline 15 & 0 & 0 & 2 & 4 & 13 & 25 & 32 & 63 & 4 & 8 & 51 & 100 \\
\hline 16 & 1 & 2 & 7 & 14 & 24 & 47 & 18 & 35 & 1 & 2 & 51 & 100 \\
\hline 17 & 1 & 2 & 5 & 10 & 8 & 16 & 31 & 61 & 6 & 11 & 51 & 100 \\
\hline 18 & 0 & 0 & 6 & 11 & 12 & 24 & 31 & 61 & 2 & 4 & 51 & 100 \\
\hline 19 & 1 & 2 & 5 & 10 & 15 & 29 & 21 & 41 & 9 & 18 & 51 & 100 \\
\hline 20 & 1 & 2 & 8 & 16 & 18 & 35 & 20 & 39 & 4 & 8 & 51 & 100 \\
\hline$\Sigma$ & 12 & 24 & 136 & 269 & 238 & 463 & 512 & 1005 & 122 & 239 & 1020 & 2000 \\
\hline Rata-rata & \multicolumn{2}{|c|}{1,2} & \multicolumn{2}{|c|}{13,45} & \multicolumn{2}{|c|}{23,15} & \multicolumn{2}{|c|}{50,25} & \multicolumn{2}{|c|}{11,95} & \multicolumn{2}{|c|}{100} \\
\hline
\end{tabular}

Berdasarkan data di atas mayoritas responden menyatakan setuju (50,25\%) bahwa Otonomi Daerah berpengaruh terhadap Peningkatan Mutu Pendidikan Menengah Atas. Selanjutnya dapat diketahui hasil deskripsi data variabel $\mathrm{X}_{1}$ sebagai berikut: Penghitungan Statistik Dasar Otonomi Daerah $\left(\mathrm{X}_{1}\right)$ dengan menggunakan SPSS for Windows Versi 17 (Hasil Data terlampir). Berdasarkan data yang dihasilkan dalam perhitungan descriptives (Lampiran) dibuat distribusi frekuensi Otonomi Daerah $\left(\mathrm{X}_{1}\right)$ sebagai berikut : Rentang kelas : $90-51=$ 39, Banyaknya kelas : $1+3.3 \log 51=6,63$ ditetapkan menjadi 7, Panjangnya kelas : 39 : 7 = 5.57dibulatkan menjadi 6. Maka hasil yang diperoleh :
Tabel.5

Distribusi Frekuensi Skor Variabelotonomi Daerah

\begin{tabular}{|c|c|c|c|}
\hline No & Interval kelas & Frekuensi & $\%$ \\
\hline 1 & $51-56$ & 2 & $4 \%$ \\
\hline 2 & $57-62$ & 3 & $6 \%$ \\
\hline 3 & $63-68$ & 12 & $23 \%$ \\
\hline 4 & $69-74$ & 12 & $23 \%$ \\
\hline 5 & $75-80$ & 18 & $35 \%$ \\
\hline 6 & $81-86$ & 3 & $6 \%$ \\
\hline 7 & $87-92$ & 1 & $1 \%$ \\
\hline
\end{tabular}

Berdasarkan data distribusi frekuensi pada tabel tersebut nilai interval diatas 
terlihat hasil jawaban responden mengenai pernyataan pada variabel Otonomi daerah mengikuti pola distribusi normal dalam mengetahui signifikansi normalitas data variabel Otonomi Daerah pada pengujian normalitas variabel penelitian.

\section{Deskripsi Data Manajemen Berbasis Sekolah $\left(\mathbf{X}_{2}\right)$}

Hasil penelitian pengaruh MBS terhadap Peningkatan Mutu Pendidikan Menengah Atas adalah sebagai berikut:

Tabel.6

Hasil Persepsi Responden MBS

\begin{tabular}{|c|c|c|c|c|c|c|c|c|c|c|c|c|}
\hline \multirow{2}{*}{ No.Item Pertanyaan } & \multicolumn{2}{|c|}{ STS } & \multicolumn{2}{|c|}{ TS } & \multicolumn{2}{|c|}{ RR } & \multicolumn{2}{|c|}{$S$} & \multicolumn{2}{|c|}{ SS } & \multicolumn{2}{|c|}{ Skor Total } \\
\hline & $\mathbf{F}$ & $\%$ & $F$ & $\%$ & $F$ & $\%$ & $F$ & $\%$ & $\mathbf{F}$ & $\%$ & $\mathbf{F}$ & $\%$ \\
\hline 1 & 0 & 0 & 4 & 7,84 & 13 & 25,5 & 34 & 66,7 & 0 & 0 & 51 & 100 \\
\hline 2 & 0 & 0 & 2 & 3,92 & 11 & 21,6 & 36 & 70,6 & 2 & 3,92 & 51 & 100 \\
\hline 3 & 0 & 0 & 2 & 3,92 & 16 & 31,4 & 31 & 60,8 & 2 & 3,92 & 51 & 100 \\
\hline 4 & 0 & 0 & 6 & 11,8 & 18 & 35,3 & 23 & 45,1 & 4 & 7,84 & 51 & 100 \\
\hline 5 & 0 & 0 & 1 & 1,96 & 18 & 35,3 & 30 & 58,8 & 2 & 3,92 & 51 & 100 \\
\hline 6 & 0 & 0 & 9 & 17,6 & 14 & 27,5 & 26 & 51 & 2 & 3,92 & 51 & 100 \\
\hline 7 & 0 & 0 & 12 & 23,5 & 15 & 29,4 & 22 & 43,1 & 2 & 3,92 & 51 & 100 \\
\hline 8 & 0 & 0 & 4 & 7,84 & 6 & 11,8 & 37 & 72,5 & 4 & 7,84 & 51 & 100 \\
\hline 9 & 1 & 1,96 & 3 & 5,88 & 8 & 15,7 & 35 & 68,6 & 4 & 7,84 & 51 & 100 \\
\hline 10 & 0 & 0 & 2 & 3,92 & 9 & 17,6 & 36 & 70,6 & 4 & 7,84 & 51 & 100 \\
\hline 11 & 0 & 0 & 1 & 1,96 & 11 & 21,6 & 34 & 66,7 & 5 & 9,8 & 51 & 100 \\
\hline 12 & 0 & 0 & 2 & 3,92 & 2 & 3,92 & 27 & 52,9 & 20 & 39,2 & 51 & 100 \\
\hline 13 & 1 & 1,96 & 1 & 1,96 & 12 & 23,5 & 30 & 58,8 & 7 & 13,7 & 51 & 100 \\
\hline 14 & 0 & 0 & 8 & 15,7 & 12 & 23,5 & 28 & 54,9 & 3 & 5,88 & 51 & 100 \\
\hline 15 & 0 & 0 & 6 & 11,8 & 7 & 13,7 & 29 & 56,9 & 9 & 17,6 & 51 & 100 \\
\hline 16 & 0 & 0 & 1 & 1,96 & 15 & 29,4 & 33 & 64,7 & 2 & 3,92 & 51 & 100 \\
\hline 17 & 0 & 0 & 6 & 11,8 & 8 & 15,7 & 33 & 64,7 & 4 & 7,84 & 51 & 100 \\
\hline 18 & 0 & 0 & 1 & 1,96 & 1 & 1,96 & 28 & 54,9 & 21 & 41,2 & 51 & 100 \\
\hline 19 & 0 & 0 & 2 & 3,92 & 3 & 5,88 & 24 & 47,1 & 22 & 43,1 & 51 & 100 \\
\hline 20 & 0 & 0 & 4 & 7,84 & 8 & 15,7 & 32 & 62,7 & 7 & 13,7 & 51 & 100 \\
\hline$\Sigma$ & 2 & 3,92 & 77 & 151 & 207 & 406 & 608 & 1192 & 126 & 247 & 1020 & 2000 \\
\hline Rata-rata & \multicolumn{2}{|c|}{0,196078} & \multicolumn{2}{|c|}{7,54902} & \multicolumn{2}{|c|}{20,29412} & \multicolumn{2}{|c|}{59,60784} & \multicolumn{2}{|c|}{12,35294} & \multicolumn{2}{|c|}{100} \\
\hline
\end{tabular}

Berdasarkan data di atas mayoritas responden menyatakan setuju (59,61\%) bahwa MBS berpengaruh terhadap Peningkatan Mutu Pendidikan Menengah Atas. Maka atas dasar data tersebut diatas, selanjutnya dapat diketahui hasil deskripsi data variabel $\mathrm{X}_{2}$ sebagai berikut:
Penghitungan Statistik Dasar MBS ( $\left.\mathrm{X}_{2}\right)$ dengan menggunakan SPSS for Windows Versi 17 (Hasil Data Terlampir). Berdasarkan data yang dihasilkan dalam perhitungan descriptives (Lampiran) dibuat distribusi frekuensi MBS ( $\left.\mathrm{X}_{2}\right)$ sebagai berikut : 1) Rentang kelas : 90 -54=36, Banyaknya kelas: 
$1+3.3 \log 51=6,63$ ditetapkan menjadi 7, dan Panjangnya kelas : $36: 7=5.14$ dibulatkan menjadi 5. Maka hasil yang diperoleh adalah sebagai berikut:

Tabel.7

Distribusi Frekuensi Skor Variabel MBS

\begin{tabular}{|c|c|c|c|}
\hline No & Interval kelas & Frekuensi & $\%$ \\
\hline 1 & $54-58$ & 1 & $1 \%$ \\
\hline 2 & $59-63$ & 3 & $6 \%$ \\
\hline 3 & $64-68$ & 4 & $8 \%$ \\
\hline 4 & $69-73$ & 8 & $16 \%$ \\
\hline 5 & $74-78$ & 18 & $35 \%$ \\
\hline 6 & $79-83$ & 13 & $25 \%$ \\
\hline 7 & $84-88$ & 2 & $4 \%$ \\
\hline 8 & $89-93$ & 2 & $4 \%$ \\
\hline & Jumlah & 51 & $100 \%$ \\
\hline
\end{tabular}

Berdasarkan data tersebut maka nilai skor untuk MBS $\left(\mathrm{X}_{2}\right)$ dapat dituangkan dalam bentuk histogram seperti gambar berikut:
Gambar. 2

Nilai Interval Kelas MBS

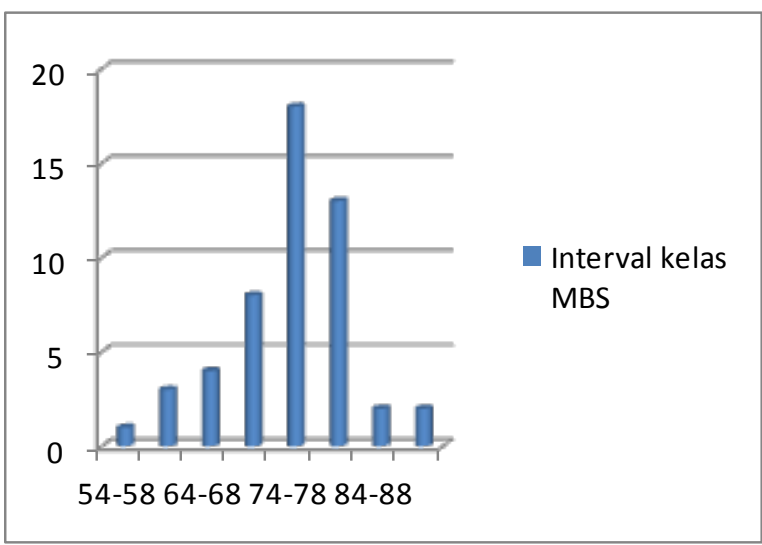

Berdasarkan data distribusi frekuensi pada gambar 2 histogram nilai interval di atas terlihat hasil jawaban responden mengenai pernyataan pada variabel MBS mengikuti pola distribusi normal dalam mengetahui signifikansi normalitas data variabel MBS pada pengujian normalitas variabel penelitian.

\section{Deskrpsi Data Mutu Pendidikan (Y)}

Berdasarkan jawaban responden mengenai Mutu Pendidikan menengah atas di wilayah Kecamatan Pagedangan diperoleh hasil sebagai berikut :

Tabel.8

Hasil Persepsi Responden Mutu Pendidikan

\begin{tabular}{|c|c|c|c|c|c|c|c|c|c|c|c|c|}
\hline \multirow{2}{*}{ No. Item Pertanyaan } & \multicolumn{2}{|c|}{ STS } & \multicolumn{2}{|c|}{ TS } & \multicolumn{2}{|c|}{ RR } & \multicolumn{2}{|c|}{$S$} & \multicolumn{2}{|c|}{ SS } & \multicolumn{2}{|c|}{ Skor Total } \\
\hline & $\mathbf{F}$ & $\%$ & $\mathrm{~F}$ & $\%$ & $\mathrm{~F}$ & $\%$ & $\mathrm{~F}$ & $\%$ & $\mathrm{~F}$ & $\%$ & $\mathrm{~F}$ & $\%$ \\
\hline 1 & 0 & 0 & 1 & 1,96 & 4 & 7,84 & 38 & 74,5 & 8 & 15,7 & 51 & 100 \\
\hline 2 & 0 & 0 & 0 & 0 & 3 & 5,88 & 34 & 66,7 & 14 & 27,5 & 51 & 100 \\
\hline 3 & 0 & 0 & 0 & 0 & 4 & 7,84 & 33 & 64,7 & 14 & 27,5 & 51 & 100 \\
\hline 4 & 0 & 0 & 3 & 5,88 & 4 & 7,84 & 31 & 60,8 & 13 & 25,5 & 51 & 100 \\
\hline 5 & 0 & 0 & 0 & 0 & 6 & 11,8 & 35 & 68,6 & 10 & 19,6 & 51 & 100 \\
\hline 6 & 0 & 0 & 5 & 9,8 & 15 & 29,4 & 27 & 52,9 & 4 & 7,84 & 51 & 100 \\
\hline 7 & 2 & 3,92 & 3 & 5,88 & 3 & 5,88 & 34 & 66,7 & 9 & 17,6 & 51 & 100 \\
\hline 8 & 7 & 13,7 & 12 & 23,5 & 15 & 29,4 & 13 & 25,5 & 4 & 7,84 & 51 & 100 \\
\hline 9 & 0 & 0 & 3 & 5,88 & 11 & 21,6 & 34 & 66,7 & 3 & 5,88 & 51 & 100 \\
\hline
\end{tabular}




\begin{tabular}{|c|c|c|c|c|c|c|c|c|c|c|c|c|}
\hline 10 & 0 & 0 & 3 & 5,88 & 9 & 17,6 & 31 & 60,8 & 8 & 15,7 & 51 & 100 \\
\hline 11 & 1 & 1,96 & 7 & 13,7 & 10 & 19,6 & 27 & 52,9 & 6 & 11,8 & 51 & 100 \\
\hline 12 & 0 & 0 & 5 & 9,8 & 19 & 37,3 & 25 & 49 & 2 & 3,92 & 51 & 100 \\
\hline 13 & 0 & 0 & 3 & 5,88 & 10 & 19,6 & 32 & 62,7 & 6 & 11,8 & 51 & 100 \\
\hline 14 & 0 & 0 & 4 & 7,84 & 7 & 13,7 & 32 & 62,7 & 8 & 15,7 & 51 & 100 \\
\hline 15 & 0 & 0 & 1 & 1,96 & 5 & 9,8 & 38 & 74,5 & 7 & 13,7 & 51 & 100 \\
\hline 16 & 0 & 0 & 0 & 0 & 5 & 9,8 & 38 & 74,5 & 8 & 15,7 & 51 & 100 \\
\hline 17 & 7 & 13,7 & 16 & 31,4 & 16 & 31,4 & 12 & 23,5 & 0 & 0 & 51 & 100 \\
\hline 18 & 1 & 1,96 & 18 & 35,3 & 18 & 35,3 & 13 & 25,5 & 1 & 1,96 & 51 & 100 \\
\hline 19 & 1 & 1,96 & 13 & 25,5 & 14 & 27,5 & 21 & 41,2 & 2 & 3,92 & 51 & 100 \\
\hline 20 & 0 & 0 & 7 & 13,7 & 20 & 39,2 & 22 & 43,1 & 2 & 3,92 & 51 & 100 \\
\hline$\Sigma$ & 19 & 37,3 & 104 & 204 & 198 & 388 & 570 & 1118 & 129 & 253 & 1020 & 2000 \\
\hline \multicolumn{2}{|c|}{1,8627451} & \multicolumn{2}{|c|}{10,19608} & 19,41176 & 55,882353 & 12,64706 & 100 \\
\hline
\end{tabular}

Berdasarkan data di atas mayoritas responden menyatakan setuju $(55,88 \%)$ ini berarti mutu pendidikan sudah berjalan cukupbaikwalaumasihterdapatkekurangan dalam pelaksanaannya. Atas dasar tabel 4.5 selanjutnya dapat diketahui hasil deskripsi data variabel Mutu Pendidikan (Y) sebagai berikut: dengan menggunakan SPSS for Windows Versi 17 (Hasil data terlampir). Berdasarkan data yang dihasilkan dalam perhitungan Descriptives (Lampiran) dibuat distribusi frekuensi Mutu Pendidikan (Y) sebagai berikut : Rentang kelas : $87-58=29$, Banyaknya kelas $\quad: 1+3.3 \log 51=6,63$ ditetapkan menjadi 7, Panjangnya kelas : 29 : $7=4.14$ dibulatkan menjadi 4. Maka hasil yang diperoleh adalah :

Tabel. 9

Distribusi Frekuensi Skor Variabel mutu Pendidikan

\begin{tabular}{|c|c|c|c|}
\hline No & Interval kelas & Frekuensi & $\%$ \\
\hline 1 & $58-61$ & 2 & $4 \%$ \\
\hline 2 & $62-65$ & 3 & $6 \%$ \\
\hline 3 & $66-69$ & 10 & $20 \%$ \\
\hline 4 & $70-73$ & 11 & $21 \%$ \\
\hline
\end{tabular}

\begin{tabular}{|c|c|c|c|}
\hline 5 & $74-77$ & 9 & $18 \%$ \\
\hline 6 & $78-81$ & 9 & $18 \%$ \\
\hline 7 & $82-85$ & 6 & $12 \%$ \\
\hline 8 & $86-89$ & 1 & $1 \%$ \\
\hline \multicolumn{2}{|c|}{ Jumlah } & 51 & $100 \%$ \\
\hline
\end{tabular}

Berdasarkan data tersebut maka nilai skor untuk Mutu Pendidikan (Y) dapat dituangkan dalam bentuk histogram seperti gambar berikut :

Gambar. 3

Nilai Interval Kelas Mutu Pendidikan

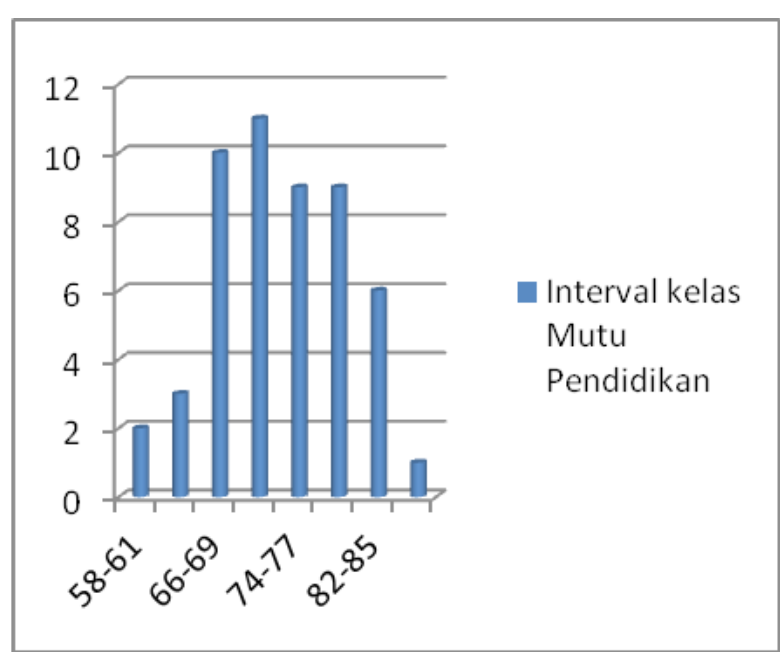


Berdasarkan data distribusi frekuensi pada gambar 3 histogram nilai interval diatas terlihat hasil jawaban reponden mengenai pernyataan pada variabel Mutu Pendidikan mengikuti pola distribusi normal dalam mengetahui signifikansi normalitas data variabel Mutu Pendidikan pada pengujian normalitas variabel penelitian

Analisis kontribusi antara variabel Otonomi Daerah dan MBS terhadap Peningkatkan Mutu Pendidikan Menengah Atas menghasilkan perhitungan yang berarti atau signifikan dan berpengaruh positif. Hubungan variabel $\mathrm{X}_{1}$ dan $\mathrm{X}_{2}$ terhadap variabel $Y$ bersifat signifikan pada tahap kepercayaan 95\% sehingga dapat berlaku secara menyeluruh atau universal. Hasil kontribusi tersebut dapat dilihat dengan cara membandingkan antara $t_{\text {hitung }}$ dan $t_{\text {tabel. }}$.

\section{Pengaruh OTDA terhadap Peningkatan Mutu Pendidikan Menengah Atas}

Berdasarkan perhitungan pada pembahasan sebelumnya dapat dihasilkan hipotesis 1 menghasilkan $t_{\text {hitung }} 5.078>t_{\text {tabel }}$ 2.010. Sehingga dalam pengujian ini Ho ditolak dan Ha diterima, artinya terdapat pengaruh antara Otonomi Daerah terhadap Peningkatan Mutu Pendidikan Menengah Atas. Dari hasil pengukuran variabel $\mathrm{X}_{1}$ terhadap variabel $\mathrm{Y}$ menghasilkan nilai koefisien korelasi $=0,582$ nilai ini jika dikonsultasikan dengan tabel interpretasi koefisien korelasi termasuk dalam hubungan yang sedang. Sedangkan berdasarkan hasil perhitungan koefisien determinasi menghasilkan nilai $\mathrm{r}^{2}=0.338$ atau $33.8 \%$. Otonomi Daerah merupakan bagian yang memiliki pengaruh terhadap Peningkatan Mutu Pendidikan.

\section{Pengaruh MBS terhadap Peningkatan Mutu Pendidikan Menengah Atas}

Berdasarkan perhitungan pada pembahasan sebelumnya dapat dihasilkan hipotesis 2 menghasilkan $t_{\text {hitung }} 4.194$

$>t_{\text {tabel }}$ 2.010. Sehingga dalam pengujian ini Ho ditolak dan Ha diterima, artinya terdapat pengaruh antara MBS terhadap Peningkatan Mutu Pendidikan Menengah Atas. Dari hasil pengukuran variabel $\mathrm{X}_{2}$ terhadap variabel $\mathrm{Y}$ menghasilkan nilai koefisien korelasi $=0,647$ nilai ini jika dikonsultasikan dengan tabel interpretasi koefisien korelasi termasuk dalam hubungan yang kuat. Sedangkan berdasarkan hasil perhitungan koefisien determinasi menghasilkan nilai $r^{2}=0.419$ atau $41.9 \%$.

\section{Pengaruh Otonomi Daerah dan Menajemen Berbasis Sekolah terhadap Peningkatan Mutu Pendidikan Menengah Atas}

Berdasarkan perhitungan pada pembahasan sebelumnya dapat dihasilkan hipotesis 3 menghasilkan $\mathrm{F}_{\text {hitung }} 23.793$ $>\mathrm{F}_{\text {tabel }} 4.04$.Sehingga dalam pengujian ini Ho ditolak dan Ha diterima, artinya terdapat pengaruh antara Otonomi Daerah dan MBS terhadap Peningkatan Mutu Pendidikan Menengah Atas. Dari hasil pengukuran variabel $\mathrm{X}_{1}$ dan $\mathrm{X}_{2}$ terhadap variabel $\mathrm{Y}$ menghasilkan nilai koefisien korelasi $=0.706$ nilai ini jika dikonsultasikan dengan tabel interpretasi koefisien korelasi termasuk dalam hubungan yang kuat. Sedangkan berdasarkan hasil perhitungan koefisien determinasi menghasilkan nilai $\mathrm{r}^{2}=0.477$ atau $47.7 \%$. 


\section{PENUTUP}

Berdasarkan hasil penelitian dan perhitungan stasistik tentang Pengaruh Otonomi Daerah dan MBS terhadap Peningkatan Mutu Pendidikan Menengah di Wilayah Kecamatan Pagedangan, dapat disimpulkan sebagai berikut: Pertama, TerdapatPengaruhotonomiDaerahterhadap Peningkatan Mutu Pendidikan Menengah Atas di Wilayah Kecamatan Pagedangan sebesar 0,582 (Sedang) dengan hubungan regresi $\hat{Y}=37.082+0.507 \mathrm{X}_{1}$ Kedua, Terdapat Pengaruh MBS terhadap Peningkatan Mutu Pendidikan Menengah Atas di Wilayah Kecamatan Pagedangan sebesar 0,647 (Kuat) dengan hubungan regresi $\hat{Y}=30.475+0.572$ $\mathrm{X}_{2}$. Ketiga, Terdapat Pengaruh Otonomi Daerah dan MBS terhadap Peningkatan Mutu Pendidikan Menengah Atas di Wilayah Kecamatan Pagedangan sebesar 0,706 (Kuat) dengan hubungan regresi $\hat{Y}=21.433+0.289 \mathrm{X}_{1}$ $+0.416 \mathrm{X}_{2}$.

Penelitian mengahsilkan sejumlah rekomendasi: Pertama, Bagi SMA/Sederajat di Kecamatan Pagedangan agar dapat memaksimalkan program MBS terutama dalam pemberdayaan masyarakat, sehingga program-program sekolah dapat efektif dan efisien serta dapat meningkatkan mutu pendidikan. Kedua, Perlu dukungan secara menyeluruh dan positif dari pemerintah daerah dalammendukung peningkatan mutu pendidikan sehingga Otonomi Pendidikan di masing-masing daerah dapat optimal dan terimplementasi dengan baik. Ketiga, Berdasarkan hasil penelitian menunjukan bahwa Pengaruh Otonomi Daerah dan MBS terhadap Peningkatan Mutu Pendidikan Menengah Atas di Wilayah Kecamatan Pagedangan positif dan kuat, Maka kiranya dapat dipertahankan. Keempat, Dengan adanya keragaman pengaruh yang dapat meningkatkan mutu pendidikan, maka kiranya penelitian ini dapat dilanjutkan kembali agar lebih sempurna.

\section{UCAPAN TERIMA KASIH}

Ucapan terima penulis sampiakan kepada berbagai pihak yang telah membantu terselenggaranya penelitian ini, diantaranya ucapan terimakasih kepada pihak sekolah (Kepala Sekolah, Guru dan Siswa) di Kecamatan Pademangan telah membantu memberikan data berupa waawancara dan kuesioner yang menjadi sampel dalam studi ini. Demikian pula kepada Ketua Sekolah Tinggi Ilmu Tarbiyah (STIT) Islamic Village Tangerang yang telah memberikan izin dalam penelitian. Penulis juga mengucapkan terima kasih kepada redaksi Jurnal Edukasi yang berkenan memberikan koreksi dan kritiknya sehingga bisa dapat diterbitkan dalam Jurnal Edukasi. 


\section{DAFTAR PUSTAKA}

Arifin, Abdurachman (1971): Theori, Pengembangan da Filosofi Kepemimpinan Kerja. Jakarta, Bhatara.

Atmosudirdjo, S. Prajudi (1986): Dasardasar Ilmu Administrasi. Jakarta, Ghalia Indonesia.

Adiwikarta, Sudardja (1988): Sosiologi Pendidikan: Isyu dan Hipotesis tentang Hubungan Pendidikan dengan Masyarakat. Jakarta, Ditjen Dikti Depdikbud.

Bafadhal, Ibrahim (2004): Manajemen Perlengkapan Sekolah Teori dan Aplikasinya. Jakarta, Bumi Aksara.

(2006): Manajemen Peningkatan Mutu Sekolah Dasar Dari Sentralisasi Menuju Desentralisasi. Jakarta, Bumi Aksara.

Bonsting, J.J. ( 2001); Quality of School. California Corwin Press.

Buchari, Alma, Ratih Hurriyati (2008): Manajemen Corporate \& Starategi Pemasaran Jasa Pendidikan. Bandung, Alfabeta.

Burhan, Nurgiyantoro, Gunawan, Marzuki (2009): Statistik Terapan, Untuk Penelitian Ilmu-ilmu Sosial. Yogyakarta, Gadjah Mada University Press.

Departemen Pendidikan Nasional Republik Indonesia (2001): Manajemen peningkatan mutu berbasis sekolah. Jakarta : Dirjen Pendidikan Dasar dan Menengah.

E. Mulyasa (2005): Menjadi Kepala Sekolah Profesional dalam Menyukseskan MBS dan KBK. Bandung , PT. Remaja Rosdakarya.

(2009): Manajemen Berbasis Sekolah. Bandung: PT. Remaja Rosdakarya.

Jalal, Fasli dan Dedi Supriadi (2001): Reformasi Pendidikan dalam Konteks Otonomi Daerah. Jakarta, Adicipta Karya Nusa.
Hadari, Nawawi (1988): Administrasi Pendidikan. Jakarta, CV Haji Masagung.

Rahim, Husni (2001): Arah Baru Pendidikan Islam di Indoensia. Jakarta, Logos.

Hidayati,Umul (2007): Permasalahan Madrasah Era Otonomi Daerah. Jakarta, Jurnal Edukasi, Volume 5. Nomor 1.

Husaini, Usman (2009): Manajemen, Edisi 3. Jakarta, PT Bumi Aksara.

J. Wayong (1961): Fungsi Administrasi Negara. Jakarta, Djambatan

Lembaga Administrasi Negara Republik Indonesia, 1993. Sistem Administrasi Negara Republik Indonesia, Jilid I. Jakarta :CV Haji Masagung.

,(1997): Sistem Administrasi Negara Republik Indonesia, Jilid II. Jakarta, PT.Toko Gunung Agung.

Minarti, Sri (2011): Manajemen Sekolah, Mengelola Lembaga Pendidikan Secara Mandiri. Yogyakarta, Ar-Ruzz Media.

Purwanto, M. Ngalim (1990): Administrasi dan Supervisi Pendidikan. Bandung : PT.Remaja Rosdakarya.

(1990):. Administrasi Pendidikan. Jakarta, Mutiara

Mohrman, Albers. et. al (1994): SchoolBased Management, Organizing for High Perpormance. San Fransisco: Jossey Bas.

Mulyono (2008): Manajemen Administrasi dan Organisasi Pendidikan. Yogyakarta, ArRuzz Media.

Fattah, Nanang (2012): Sistem Penjamin Mutu Pendidikan. Bandung, PT.Remaja Rosdakarya.

Nata, Abuddin (2001): Pendidikan Berbasis Masyarakat dalam Perspektif Islam Jakarta, Jauhar Jurnal Pemikiran Islam Kontekstual. Volume 2. Nomor 2. 
Nurkholis (2003): Manajemen Berbasis Sekolah, Teori, Modeldan Aplikasi. Jakarta, Gramedia Widiasarana Indonesia.

Onisimus Amtu (2011): Manajemen Pendidikan di Era Otonomi Daerah. Bandung, Alfabeta.

Rodney T. Ogawa \& Paula A. White, dalam Susan Albers Mohman (1994): School Based Management, Organizing for High Performance. San Francisco, Jossey-Bass Publisher.

Rosyidi, Imron (2001): Manajemen Pendidikan. Jakarta, WSP Group Jakarta.

Rohiat (2009): Manajemen Sekolah, Teori Dasar dan Praktik. Bandung, PT.Refika Aditama.

Sagala, Syaiful (2007): Manajemen Statejik dalam Peningkatan Mutu Pendidikan. Bandung, Alfabeta.

_-_-_-_, (2008): Administrasi Pendidikan Kontemporer. Bandung, Alfabeta.

Sallis, Edward (2002): Total Quality Management in Education. Jakarta, Gramedia.

Suti, Marus (2011): Strategi Peningkatan Mutu di Era Otonomi Pendidikan, Jurnal MEDTEK, Volume 3. Nomor 2.
S. Pamudji (1983): Ekologi Administrasi Negara. Jakarta , Bumi Aksara.

Sondang P. Siagian (1974): Administrasi Pengembangan. Jakarta, Gunung Agung.

Staf Dosen BPA-UGM (1970): Buku Petunjuk Administrasi Fakultas pada Universitas Gajah Mada. Yogyakarta, UGM.

Sugiyono (2008): Metode Penelitian Kuantitatif Kualitatif Dan R \&D. Bandung, Alfabeta.

Suryosubroto, B (2004): Manajemen Pendidikan di Sekolah. Jakarta, Rineka Cipta.

Tim Dosen Administrasi Pendidikan UPI (2010): Manajemen Pendidikan. Bandung, Alfabeta.

Tim Penyusun (2002): Kamus Besar Bahasa Indonesia. Jakarta, Balai Pustaka.

UUSPN Tentang Sistem Pendidikan Nasional Nomor 20 Tahun 2003.

Ubaedillah, A. (2014): Pendidikan Kewarganegaraan (civic Education). Jakarta, Kencana.

Wayne K.Hoy, Cecil G.Miskel (2005): Educational Administration. New York, Mc.GRAW- Hill Internasional Edition.

Umaedi (2004): Manajemen Mutu Berbasis Sekolah/Madrasah. Jakarta, Pusat Kajian Manajemen Mutu Pendidikan. 
